CLINICAL STUDY

\title{
Impairment of insulin receptor signal transduction in placentas of intra-uterine growth-restricted newborns and its relationship with fetal growth
}

\author{
M E Street, I Viani, M A Ziveri, C Volta, A Smerieri and S Bernasconi \\ Department of Paediatrics, University Hospital of Parma, 43126 Parma, Italy \\ (Correspondence should be addressed to M E Street who is now at Dipartimento dell'Età Evolutiva, Via Gramsci, 14, 43100 Parma, Italy; \\ Email: mariaelisabeth.street@uniprit)
}

\begin{abstract}
Objective: Intra-uterine growth restriction (IUGR) is related to a higher incidence of type 2 diabetes mellitus. We previously reported reduced adiponectin and increased interleukin 6 (IL6) concentrations in IUGR placentas, which are features of insulin resistance. We aimed to investigate placental insulin receptor (IR) function and activation in human placenta and subsequently the relationships of insulin signalling peptides with placental protein content in IL6, insulin, resistin and adiponectin, and with parameters of fetal growth.

Design and methods: Whole villous tissue was collected from 18 IUGR and 24 appropriate for gestational age (AGA) placentas of comparable gestational age. Insulin signalling peptides, suppressors of cytokine signalling-2 (SOCS2), insulin, adiponectin, resistin, and IL6 concentrations were determined by using western immunoblotting or specific research kits.

Results: The amount of total IR was similar in both groups but activated IR significantly higher in IUGR. Total IR substrate-1 (IRS1) was increased in IUGR, whereas total IRS2 and activated IRS1 were similar. AKT content was reduced and activated AKT was undetectable in IUGR placentas. c-Jun $\mathrm{N}$-terminal kinase content was reduced in IUGR. Total and activated ERK1/2 was similar in IUGR and AGA groups, and total SOCS2 was increased in IUGR. IL6 lysate concentrations correlated with AKT content and activated IR. Correlations were found also with adiponectin and resistin. SOCS2 correlated negatively with all growth parameters at birth.

Conclusions: IR was more activated in placentas of IUGR compared with AGA; however, signal transduction downstream of the receptor was impaired. The increase in activated IR could be in favour of a compensatory mechanism to increase insulin sensitivity. Close relationships of insulin action in placenta with fetal growth were shown.
\end{abstract}

European Journal of Endocrinology 164 45-52

\section{Introduction}

The failure of a fetus to attain its expected fetal growth at any gestational age is defined as intra-uterine growth retardation (IUGR). Subjects born with IUGR have been reported to have an increased incidence of developing cardiovascular disease, hypertension and type 2 diabetes mellitus in adulthood compared with the general population (1). These features are shared with obese subjects, and derive primarily from increased insulin resistance (2), which is related by association with high serum concentrations of pro-inflammatory cytokines and low adiponectin concentrations $(3,4)$.

Adiponectin concentrations have been found reduced in placentas of women with gestational diabetes (5). Moreover, in gestational diabetes, the insulin receptor (IR) and some of the main peptides involved in insulin signal transmission were reported to be increased $(6,7)$.
Insulin resistance was reported recently in human pre-eclamptic placentas also, and was related to impaired insulin signalling (8). Interestingly, both gestational diabetes and pre-eclampsia are characterised by an increased inflammatory status $(7,9)$.

We recently reported significantly lower adiponectin and significantly higher interleukin 6 (IL6) concentrations in placental lysates of IUGR newborns (10).

Moreover, we showed that human IUGR subjects have increased insulin-like growth factor-binding protein-1 (IGFBP1) and IGFBP2 in the placenta compared with appropriate for gestational age (AGA) newborns. The IGF2 peptide was also significantly increased in IUGR, and it could be speculated that IGF2 could be increased to compensate for reduced insulin bioactivity $(10,11)$.

However, it is unknown at present in humans, in IUGR, whether the placenta shows features of insulin resistance. Insulin is a well-recognised in utero 
growth factor besides a placental growth factor (12), and IL6 and other pro-inflammatory cytokines such as TNF- $\alpha$ are responsible for molecular mechanisms of insulin resistance $(13,14)$. The insulin signalling pathway is well known to control glucose uptake, synthesis, protein synthesis, and cell proliferation, differentiation and apoptosis.

In vitro studies have shown that IL6 induces decreased phosphorylation of IR substrate-1 (IRS1) and association of subunit p85 of the PI3-kinase with IRS1, in response to physiological concentrations of insulin. Furthermore, the insulin-dependent activation of AKT is markedly reduced with subsequent inhibition of glycogen synthesis (13), and chronic infusion of IL6 in murine liver induces insulin resistance through different mechanisms (15).

In vitro studies have shown that IL6 also stimulates ERK and c-Jun N-terminal kinase (JNK) pathways (16). ERK1/2 is part of the MAPK cascade, which is involved in controlling cell growth and differentiation. JNK1/2 MAPKs are also part of this signalling pathway. JNK1/2 activation appears to be involved in serine phosphorylation of IRS1 and subsequently insulin resistance on glucose uptake (17).

IL6 is also known to induce a family of negative regulators of cytokine signal transduction, the suppressors of cytokine signalling (SOCS) which have been shown to directly interact with the IR or IRS1 inhibiting insulin signal transduction $(18,19)$. SOCS2 is also an inhibitor of the GH receptor, and $\mathrm{GH}$ is also part of the interplay in the regulation of insulin sensitivity (20).

This study aimed to assess whether IR activation and signal transduction showed changes in the placenta of IUGR compared with AGA newborns of comparable gestational age, and to establish relationships of the insulin signalling peptides with placental protein content in IL6, insulin, resistin and adiponectin.

Relationships of single peptides with placental weight and parameters of fetal growth were also investigated.

\section{Methods}

\section{Subjects}

Eighteen IUGR and 24 AGA births of comparable gestational age ( $35.3 \pm 0.5$ vs $36.5 \pm 0.4$ weeks respectively NS) were followed during pregnancy. All pregnancies were dated correctly by ultrasound during the first trimester of gestation. AGA birth newborns were defined on the basis of a normal birth weight $(<80$ th and $>10$ th centiles) with respect to the Italian standards (21), a normal pregnancy and the absence of maternal risk factors.

The IUGR pregnancies were diagnosed by ultrasound according to the following criteria: abdominal circumference $<10$ th centile and/or shift of fetal growth with a reduction of abdominal circumference with respect to the measure taken during the 20th week of gestation (21). In IUGR subjects, Doppler velocimetry was altered in almost all cases in the placenta and/or foetus site (22). The diagnosis of IUGR was made within the 32nd week of gestation and was ascribed to a probable placental cause after excluding other causes as infections, chromosomal abnormalities, genetic syndromes, maternal malnutrition, substance abuse, gross placental abnormalities and multiple fetuses. No cases with hypertension, gestational diabetes or reduced amount of amniotic fluid were included in the study.

All neonates, both IUGR and controls, were delivered by elective caesarean section (CS).

The causes of preterm birth ( $<38$ weeks of gestation) in the AGA newborns were intra-hepatic colestasis in a woman who had underwent a previous CS, premature rupture of membranes with breech presentation and delivery within $4 \mathrm{~h}$ with no signs of infection. Elective CS in these subjects was performed because of refusal of vaginal delivery for psychological reasons, or because of a previous CS.

At birth, the following information was collected: age of the mother, weight at birth of both parents, body mass index (BMI) of the mother before pregnancy, previous gynaecological history, medical history during pregnancy, fetal biophysical data (exact duration of pregnancy and growth trend), clinical data at delivery (indication for CS, neonatal data as sex, weight, length, head circumference, APGAR score, acid-base equilibrium and perinatal data), weight and macroscopic aspect of the placenta. The main clinical features of both IUGR and AGA newborns are shown in Table 1.

\section{Laboratory methods}

Collection of biological material Previously collected placental samples from IUGR and AGA births were used. The placental fragments were treated as previously described $(10,11)$. Briefly, four-six fragments/neonate were taken at birth close to the insertion of the umbilical cord and at the fetal side of the placenta. These fragments did not include areas involving infarction

Table 1 Clinical data of newborns born from pregnancies complicated with IUGR and AGA at birth. Data are mean \pm S.E.M.

\begin{tabular}{lcc}
\hline & IUGR & AGA \\
\hline Males/females & $12 / 6$ & $15 / 9$ \\
Gestational age (years) & $35.3 \pm 0.5$ & $36.5 \pm 0.4$ \\
Mothers' chronological age (years) & $31.8 \pm 1.3$ & $33.2 \pm 0.8$ \\
Mothers' BMl at the beginning of & $22.6 \pm 0.9$ & $22.4 \pm 0.6$ \\
$\quad$ pregnancy $\left(\mathrm{kg} / \mathrm{m}^{2}\right)$ & $440 \pm 55$ & $543 \pm 41$ \\
Placental weight $(\mathrm{kg})$ & $1.4 \pm 0.1^{*}$ & $2.85 \pm 0.1$ \\
Birth weight $(\mathrm{kg})$ & $39.7 \pm 1.4^{*}$ & $49.1 \pm 0.6$ \\
Birth length (cm) & $29.4 \pm 0.7^{*}$ & $34.3 \pm 0.6$ \\
Head circumference $(\mathrm{cm})$ & & \\
\hline
\end{tabular}

${ }^{*} P<0.05$ vs AGA. 
and calcification, and decidua, marginal and chorion were avoided. The fragments were immediately rinsed in ice-cold sterile saline solution and placed in RNA Later (Calbiochem-Novabiochem Corporation, affiliate of Merck HgaA, Darmstadt, Germany), kept on ice and placed within $15 \mathrm{~min}$ at $-20^{\circ} \mathrm{C}$ and subsequently at $-80{ }^{\circ} \mathrm{C}$ until tissue lysis.

Placenta lysis, total protein determination and immunoprecipitation The samples of placenta were sliced and homogenised in a lysis buffer at $0{ }^{\circ} \mathrm{C}$ (modified RIPA buffer: $50 \mathrm{mM}$ Tris- $\mathrm{HCl}, 1 \% \mathrm{NP}-40,0.25 \% \mathrm{Na}$ deoxycholate, $150 \mathrm{mM} \mathrm{NaCl}, 1 \mathrm{mM}$ EDTA, $1 \mathrm{mM}$ phenylmethylsulphonyl fluoride, $1 \mu \mathrm{g} / \mathrm{ml}$ each of aprotinin, leupeptin and pepstatin, $1 \mathrm{mM} \mathrm{Na}_{3} \mathrm{VO}_{4}$ and $1 \mathrm{mM}$ $\mathrm{NaF}$ ). The total protein content was measured using the 'microassay Bio-Rad' protocol (Bio-Rad Lab), and the standard reference curve was obtained using bovine albumin. Immunoprecipitation was performed using a protein A/G-based method (Santa Cruz Biotechnology, Inc., Santa Cruz, CA, USA). Briefly, equal amounts of placenta lysates ( $1 \mathrm{mg}$ total protein) were subjected to immunoprecipitation overnight at $4{ }^{\circ} \mathrm{C}$ using $1 \mu \mathrm{g}$ specific antibodies, anti-IRS1 and anti-IRS2 (Upstate Biotechnology, Lake Placid, NY, USA). The resulting immunocomplexes were adsorbed to protein $A / G$ Sepharose beads overnight at $4{ }^{\circ} \mathrm{C}$ as recommended by the manufacturer, and then eluted with electrophoresis sample buffer (Invitrogen).

SDS-PAGE and western blotting Equal amounts of immunoprecipitate or protein from the whole lysates were subjected to electrophoresis using precast gels according to molecular weight (NOVEX, Invitrogen). The resolved proteins were electrophoretically transferred to nitrocellulose membranes (Hybond-C Extra, Amersham Biosciences Ltd) and hybridised with the following antibodies: anti-IRS1 (Upstate Biotechnology, Inc., Millipore Corporate, Billerica, MA, USA; dilution $0.5 \mu \mathrm{g} / \mathrm{ml}$ ), anti-phospho IRS1 (Y896) (Upstate Biotechnology, Inc., Millipore Corporate; dilution 1:1000), anti-phospho IRS1 (S307) (Upstate Biotechnology, Inc., Millipore Corporate; dilution 1:1500), anti-IRS2 (Upstate Biotechnology, Inc., Millipore Corporate; dilution 1:1000), anti-ERK1/2, anti-P-ERK1/2 (Y204/ 187-T 202/185) (Santa Cruz Biotechnology, Inc.; dilution 1:200) and anti-SOCS2 (BioLegend, San Diego, CA, USA; dilution, 1:1000). Single peptides (Upstate Biotechnology, Inc., Millipore Corporate) and/or normal human serum were used as positive controls. Anti $\beta$-actin (Santa Cruz Biotechnology, Inc.; dilution 1:200) was used as further control.

As second antibodies, an anti-rabbit or anti-mouse HRP-linked whole antibody was used as appropriate (Amersham Life Science), diluted in 1\% BSA in PBS/Tween (1:4000 anti-rabbit; 1:3000 anti-mouse).
The proteins were then analysed by ECL (Amersham Pharmacia Biotech) on autoradiographic film (Kodak BIOMAX). The differences between IUGR subjects and controls were analysed by scanning densitometry using the programme UN-SCAN-IT gel, version 5.1 (Silk Scientific Corporation, Orem, UT, USA). Band intensity was expressed in arbitrary units (optic densitometry units, ODU).

Assays on placenta lysates The total amount of IR ( $\beta$ subunit) was measured using a specific research ELISA kit (BioSource International, Camarillo, CA, USA). The intra-assay coefficient of variation (CV) was $5.4 \%$, and the inter-assay was $8.2 \%$. The sensitivity of the method was $0.5 \mathrm{ng} / \mathrm{ml}$. Activation of the IR (pYpY1162/1163) was assessed using a specific ELISA kit by BioSource International. The intra-assay CV was $4.9 \%$, and the inter-assay CV was $6.6 \%$. The sensitivity of the method was $0.8 \mathrm{U} / \mathrm{ml}$. AKT (total) was measured using a specific research ELISA kit (BioSource International). The intra-assay $\mathrm{CV}$ was $7.7 \%$, and the interassay CV was $9.3 \%$. The sensitivity of the method was $<0.1 \mathrm{ng} / \mathrm{ml}$. Activated AKT (pS473) was measured using a specific research ELISA kit (BioSource International). The intra-assay $\mathrm{CV}$ was $6.9 \%$, and the interassay CV was $8.3 \%$. The sensitivity of the method was $0.8 \mathrm{U} / \mathrm{ml}$.

JNK (total) was measured using a specific research ELISA kit (BioSource International). The intra-assay CV was $8.8 \%$, and the inter-assay $\mathrm{CV}$ was $9.2 \%$. The sensitivity of the method was $<0.15 \mathrm{ng} / \mathrm{ml}$. Activated JNK (pTpY 183/185) was measured using a specific research ELISA kit (BioSource International). The intraassay CV was $8.6 \%$, and the inter-assay CV was $9.8 \%$. The sensitivity of the method was $<0.8 \mathrm{U} / \mathrm{ml}$. IL6 was measured using an ultrasensitive ELISA method (Quantikine HS, R\&D Systems, Minneapolis, MN, USA) as previously described $(10,11)$. Insulin was assayed using a specific IRMA assay (DiaSorin S.p.A., Saluggia, Italy) as previously described (10). Resistin was assayed using ultrasensitive ELISA methods (Quantikine HS, R\&D Systems), and adiponectin was assayed using a specific ELISA research kit (Quantikine HS, R\&D Systems) as previously described (11).

Insulin, resistin, IL6 and adiponectin were assayed prior to this study (10).

All concentrations of placental lysates were normalised for milligrammes of total protein. We previously showed, in addition, that total protein content was similar in IUGR and AGA placentas (11).

\section{Ethical approval}

Informed consent was obtained from the mothers. The study was approved by the ethics committee of the University of Parma Medical School. 


\section{Statistical analysis}

The statistical analysis was performed using SPSS 17.1 for Windows (SPSS, Inc., Chicago, IL, USA) and Statistica 8.0 (StatSoft, Inc., Tulsa, OK, USA). The normal distribution of the data was determined using the Kolmogorov-Smirnov/Lilliefors test. These data were analysed using an unpaired t-test. IL6 and individual peptides downstream from the IR were not normally distributed and were analysed using the Wilcoxon rank sum test. The correlation analysis was performed using Pearson's or Spearman's coefficients, as appropriate, followed by Bonferroni's correction. Only significant correlations are reported in the text.

Data are expressed as mean \pm s.E.M. unless otherwise stated.

\section{Results}

\section{Differences between placentas from IUGR and AGA newborns}

Total and activated IR in lysates IR content was similar in IUGR and AGA placentas $(4.00 \pm 1.56$ vs $6.72 \pm 1.64 \mathrm{ng} / \mathrm{mg}$ respectively), whereas the amount of activated IR was greater in IUGR compared with AGA placentas $(4.94 \pm 1.84$ vs $1.54 \pm 0.33 \mathrm{U} / \mathrm{mg}$ respectively, $P<0.05$; Fig. $1 \mathrm{~A}$ and $\mathrm{B}$ ); however, the activated/ total IR ratio was higher but not significantly different in the IUGR (1.23 \pm 1.4 vs $0.22 \pm 0.05 \mathrm{U} / \mathrm{ng}$ in AGA).

Mediators of IR signal transduction IRS1 content was significantly increased in IUGR $(147.80 \pm 13.43$ vs $75.11 \pm 13.57$ ODU in AGA, $P<0.05$; Fig. 2A), whereas the amount of IRS2 was similar in IUGR and AGA $(68.19 \pm 10.56$ vs $75.11 \pm 13.57$ ODU respectively). Tyrosine phosphorylated IRS1 was increased but not significantly different in IUGR compared with AGA $(223.62 \pm 14.35$ vs 175.99 \pm 12.82 ODU respectively). The activated/total IRS1
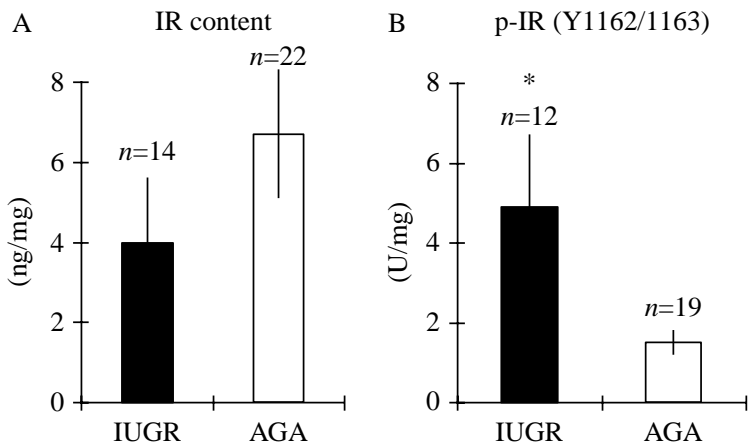

Figure 1 Insulin receptor (IR) content in placental lysates from intrauterine growth-restricted (IUGR) and appropriate for gestational age (AGA) pregnancies was similar (A), whereas activated IR was significantly increased in placental lysates from IUGR compared with AGA placentas. ${ }^{*} P<0.05$ versus $A G A(B)$.

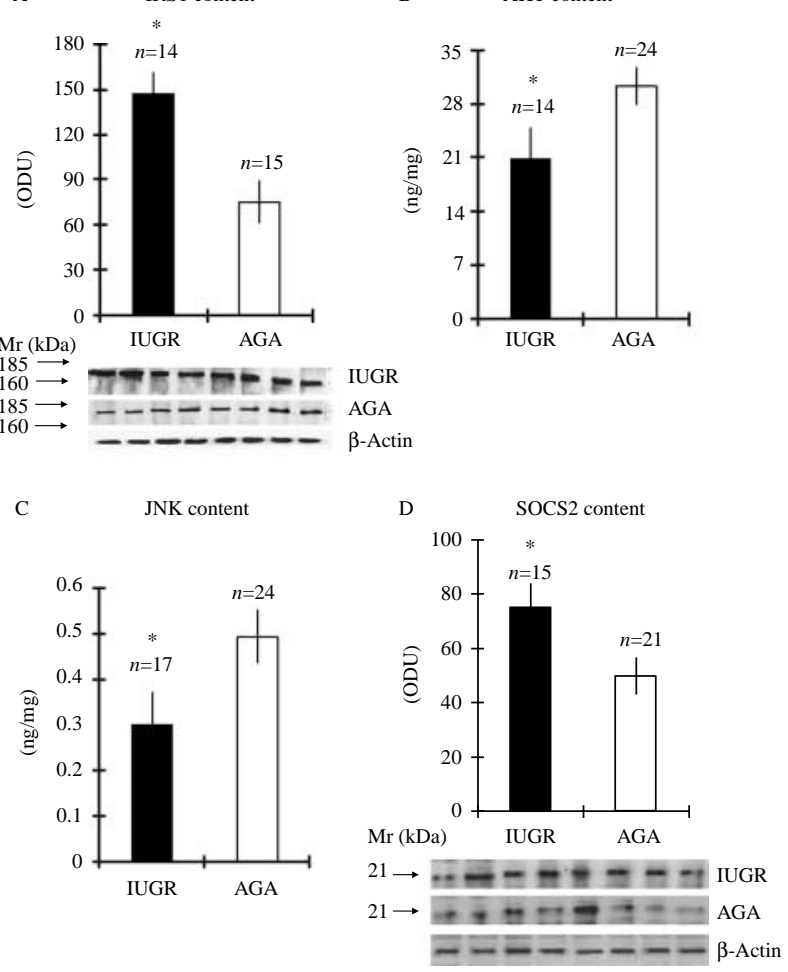

Figure 2 Insulin receptor substrate-1 (IRS1) content in placental lysates from IUGR newborns was significantly increased compared with AGA pregnancies. IRS1 in the bar graph is expressed in optic densitometry units (ODU), and represents the mean \pm s.E.M. of all experiments in both groups. Below are representative western immunoblots of samples from both IUGR and AGA, as specified in methods. ${ }^{*} P<0.05$ versus AGA (A). AKT content in placental lysates from IUGR was reduced compared with AGA pregnancies. ${ }^{\star} P<0.05$ versus AGA (B). c-Jun $\mathrm{N}$-terminal kinase (JNK) content in placental lysates from IUGR was reduced compared with AGA pregnancies. ${ }^{*} P<0.05$ versus AGA (C). SOCS2 was significantly increased in placental lysates from IUGR compared with AGA pregnancies. In the upper part of the figure, the bar graph represents the mean \pm S.E.M. of all experiments in both groups, and data are expressed in optic densitometry units (ODU). Below are representative western immunoblots of placental lysates from both groups. ${ }^{*} P<0.05$ versus AGA (D).

ratio was similar in IUGR and AGA placentas ( $1.51 \pm 0.17$ vs $2.34 \pm 0.47$ ODU respectively).

Serine phosphorylated IRS1 was undetectable in all AGA, whereas the corresponding $170 \mathrm{kDa}$ band was visible in some IUGR placental lysates ( $n=5 / 18$, data not shown).

AKT content, in IUGR, was significantly reduced $(20.82 \pm 3.96$ vs $30.37 \pm 2.40 \mathrm{pg} / \mathrm{mg}$ in AGA, $P<0.05$; Fig. 2B), whereas activated AKT was substantially undetectable (measurable only in two samples/18) compared with AGA $(2.73 \pm 0.46 \mathrm{U} / \mathrm{mg})$.

ERK1 and 2 content and activated ERK1 (94.51 \pm 15.46 vs $93.59 \pm 8.21$ ODU in IUGR and AGA respectively) and $2(122.66 \pm 39.50$ vs $105.12 \pm 8.68$ ODU in IUGR and AGA respectively) by tyrosine and threonine phosphorylation were not different in IUGR compared with AGA placentas. 
The activated/total ERK1 ratio was similar in IUGR and AGA placentas $(1.61 \pm 0.10$ vs $0.67 \pm 0.07$ ODU respectively, NS) as also the activated/total ERK2 ratio $(1.08 \pm 0.2$ vs $1.25 \pm 0.3$ ODU respectively, NS).

JNK1/2 content was significantly lower in IUGR

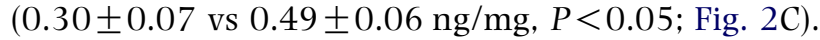
Activated tyrosine phosphorylated JNK1/2 was lower but was not significantly different in IUGR compared with AGA placentas $(0.02 \pm 0.007$ vs $0.72 \pm 0.22 \mathrm{U} / \mathrm{mg}$ respectively, $P<0.05)$ with a significant decreased activated/total JNK ratio in IUGR $(0.067 \pm 0.004$ vs $0.16 \pm 0.03 \mathrm{U} / \mathrm{ng}$ in AGA, $P<0.05)$.

The $21 \mathrm{kDa}$ band, corresponding to SOCS2, was significantly increased in IUGR compared with AGA placentas $(75.06 \pm 8.72$ vs $49.69 \pm 6.78$ ODU respectively, Fig. 2D).

\section{Correlation analysis}

Correlations with IL6 in placenta The activated IR content was correlated with IL6 concentrations in lysates ( $r=0.81 ; P=0.001$; Fig. 3$)$.

AKT content was negatively correlated with IL6 $(r=-0.35 ; P=0.05)$.

Correlations between peptides in placenta Total and activated IR contents were correlated as expected $(r=0.45 ; P=0.02)$. The IR content was correlated with insulin $(r=0.62 ; P=0.03), \quad$ resistin $\quad(r=0.45$; $P=0.018)$ and adiponectin concentrations in placental lysates $(r=-0.38 ; P=0.044)$. The activated IR content was correlated with IRS1 content $(r=0.73$; $P=0.011)$, activated JNK $(r=0.38 ; P=0.050)$ and resistin $(r=0.45 ; P=0.018)$ in lysates.

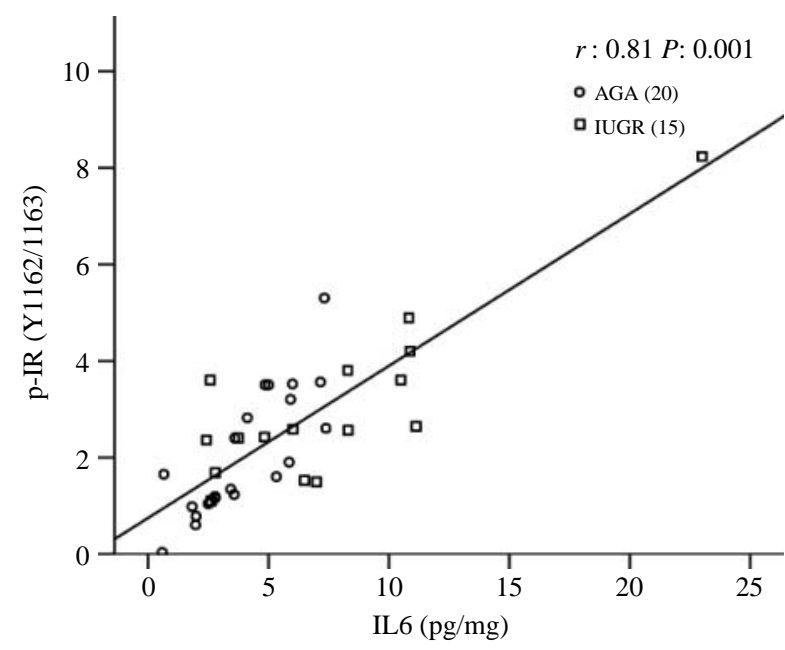

Figure 3 Normalised IL6 placental content was positively correlated with activated insulin receptor placental content (p-IR(pYpY1162/1163)). AGA newborns are represented as open circles, and IUGR newborns as open squares.
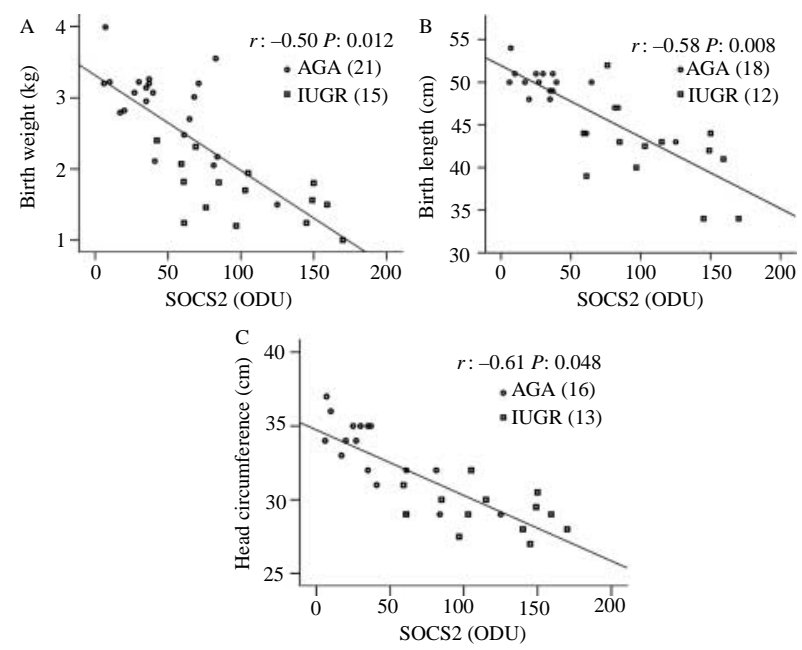

Figure 4 SOCS2, expressed in optic densitometry arbitrary units (ODU), was negatively correlated with birth weight $(A)$, birth length (B) and head circumference (C) of all newborns. AGA newborns are represented as open circles, and IUGR newborns as open squares.

Activated IRS1 was correlated with IRS1 content $(r=0.64 ; P=0.048)$, insulin $(r=0.61 ; P=0.044)$ and adiponectin concentrations in lysates $(r=-0.66$; $P=0.005)$, and with activated JNK $(r=0.56$; $P=0.018)$.

IRS2 content was correlated with adiponectin concentration $(r=0.54 ; P=0.015)$.

JNK1/2 content was correlated with adiponectin concentration $(r=0.41 ; P=0.024)$.

Correlations of placental peptides with placental weight and growth parameters at birth Placental weight was correlated with IRS2 $(r=0.37 ; P=0.043)$ and AKT placental contents $(r=0.48 ; P=0.003)$.

Birth weight was correlated with the amount of activated IR $(r=-0.37 ; P=0.042)$, JNK $1 / 2$ content $(r=0.39 ; P=0.034)$ and SOCS $2(r=-0.50 ; P=0.012$; Fig. 4A).

Birth length was correlated with the activated IR content $(r=-0.56 ; P=0.004)$ and SOCS2 $(r=-0.58 ; P=0.008$; Fig. $4 \mathrm{~B})$.

Head circumference was correlated with the activated IR content $(r=-0.64 ; P=0.005)$, SOCS2 $(r=-0.61 ; P=0.046 ;$ Fig. $4 C)$ and the activated/total AKT ratio $(r=0.88 ; P=0.008)$.

The correlations between the auxological parameters at birth and the above-described peptides, except SOCS2, are summarised in Table 2.

\section{Discussion}

This study explored for the first time IR signal transduction in placentas of IUGR compared with AGA pregnancies. The findings showed increased activated IR content in IUGR compared with AGA 
Table 2 Correlation coefficients $(r)$ and $P$ values of auxological parameters at birth with insulin signalling peptides, except SOCS2, of both IUGR and AGA newborns.

\begin{tabular}{llrc}
\hline & Variables & \multicolumn{1}{c}{$\boldsymbol{r}$} & $\boldsymbol{P}$ value \\
\hline Birth weight $(\mathrm{kg})$ & IR content & -0.37 & 0.043 \\
& JNK1/2 content & 0.39 & 0.034 \\
Birth length $(\mathrm{cm})$ & Activated IR content & -0.56 & 0.004 \\
Head circumference & IR content & -0.64 & 0.005 \\
$(\mathrm{~cm})$ & Activated/total & 0.88 & 0.008 \\
& AKT ratio & & \\
\hline
\end{tabular}

placentas but reduced signal transduction with reduced AKT activation, possibly affecting mainly glucose and protein synthesis.

Similar ERK1/2 activity, but reduced JNK1/2 content and activation, was demonstrated suggesting that cell growth, proliferation and differentiation could also be impaired in IUGR placentas. Correlation analysis showed relationships between changes in IR signal transduction and IL6 concentrations in placental tissue. Finally, the amount of activated IR, AKT, JNK1/2 and SOCS2 showed clear relationships with fetal growth parameters at birth.

The human placenta is known to contain a large number of IRs, and a metabolic action of these receptors via fetal control has been previously hypothesised $(14,15)$. Gestational age was comparable in the two groups investigated to avoid changes in IR and insulin content, related with the duration of pregnancy (12).

The similar activated IRS1 content and the detectable serine phosphorylated IRS1 in IUGR is a first step to suggest that insulin signalling might be impaired just downstream of the activated IR. This process is a common finding in insulin-resistant states and in type 2 diabetes mellitus $(23,24)$. IRS1 protein is considered to be crucial for regulation of glucose uptake in insulinsensitive tissues, and our findings in IUGR placentas could suggest reduced glucose uptake.

Total and activated AKT were significantly decreased in IUGR placentas, and data suggested a very low activated/total AKT ratio in IUGR compared with AGA placentas. This finding is in agreement with findings in trophoblast cell lines and in IUGR pregnancies due to pre-eclampsia, a condition, however, excluded from our studies (25). Moreover, these same authors showed, using AKT1 null mice, a central role for AKT in IUGR in association with endoplasmic reticulum stress (25). AKT is also part of the signalling pathway of the type 1 IGF receptor. At variance with our findings, AKT content was described to be reduced, whereas activated AKT unchanged in IUGR placentas (26). These slight differences could be owe to the smaller number of placentas these authors investigated, and to the fact that in that study, preterm IUGR pregnancies were compared with AGA placentas at term. The negative relationship between AKT and IL6 confirms in vivo, in humans, previous in vitro findings where insulin-dependent activation of AKT was markedly inhibited by IL6 treatment (13).

ERK1/2 content was similar in IUGR and AGA and failed to be activated in IUGR at variance with data showing ERK1/2 activation after IL6 administration to specific brain regions of rats (27), and studies in human umbilical vein endothelial cells (28). We also failed to identify any relationship with IL6 concentration in placenta, possibly suggesting tissue- and species-specific effects of IL6. We also speculate that the absent activation could be due to crosstalk among receptors, and the increased SOCS2 could account for down-regulation of signalling through the GH and IGF type 1 receptors.

We expected JNK to be activated and/or increased by the high IL6 concentrations in IUGR placentas, and to be possibly implicated in IRS1 serine phosphorylation, thus inhibiting insulin action $(16,17)$; however, JNK content and activated JNK were reduced in the IUGR placentas. This suggests an impairment of the MAPK pathway being significantly reduced in IUGR. The absence of a relationship with IL6 is at variance with previous in vitro data (16). The relationship we detected between JNK and adiponectin could suggest a link with insulin action or sensitivity in the placenta. These latter findings are altogether similar to those reported by Laviola et al., (26) although less marked.

The significant increase in SOCS2 in IUGR placentas could be consistent with both reduced insulin action and reduced GH action in IUGR placentas (29). Moreover, SOCS2 can bind the type 1 IGF1 receptor both in vivo and in vitro, suggesting that it can downregulate the bioactivity of this receptor also $(20,30)$.

We did not find a direct relationship of SOCS2 with IL6 concentration in placental lysates, and must therefore hypothesise SOCS2 activation by a different mechanism; however, SOCS2 could certainly play an important role in both insulin action through a direct action on the IR or IRS1 $(20,29,30)$, and indirectly by inhibiting the GH receptor (31). GH action is in fact recognised as an important factor regulating insulin sensitivity (32). Placental regulation is unknown and certainly, it is largely dependent on specific placental features (12).

SOCS2 knockout mice have gigantism (20). The increased concentrations in IUGR placentas and negative relationships with all growth parameters at birth are in line with previous experimental evidence, and demonstrate in humans the importance of this mechanism for fetal growth.

A role for insulin on fetal and placental growth is well established $(10,12)$. Insulin concentration in lysates was directly related with the total amount of IR and activated IRS1 but not with other post-receptor mediators suggesting interferences of other signalling peptides, possibly signalling through different receptors, modifying the final effect of insulin. Our findings are in agreement with those in placentas from pregnancies complicated with gestational diabetes (33). 
The relationship of resistin with total and activated IR content, and the correlations of adiponectin with IR content, activated IRS1, IRS2 and JNK suggest that both peptides play a role in placenta in regulating insulin action, and are in line with published reports (34-36). Findings are both in agreement with previous data (5), and at variance with recent findings in placenta of women with gestational diabetes (37).

Our data showed a direct relationship of placental weight with IRS2 and AKT confirming that insulin is also an important placental growth factor (12). The relationships we described between activated IR, JNK, SOCS2 and total/activated AKT ratio and growth parameters at birth confirm that insulin signalling through the IR, and in particular via AKT activation, was crucial for fetal growth during pregnancy.

In IUGR placentas, the overall data showed reduced insulin action where the increase in activated IR could be in favour of a compensatory mechanism to increase insulin sensitivity in a condition where insulin signal transduction is impaired downstream the receptor. Finally, these findings confirmed the importance of insulin signalling and SOCS2 for normal fetal growth. It remains to be elucidated how and for how long these placental changes influence post-natal modifications related with insulin sensitivity.

\section{Declaration of interest}

The authors declare that there is no conflict of interest that could be perceived as prejudicing the impartiality of the research reported.

\section{Funding}

The present study is funded by Research funds, Department of Paediatrics, University of Parma, Italy.

\section{Author contribution statement}

M E Street designed and led the study, analysed the data, drafted, developed and finalised the manuscript; I Viani, M A Ziveri and A Smerieri carried out the assays, discussed the findings, prepared the figures and helped to edit the manuscript; C Volta and S Bernasconi discussed the findings, helped to develop and edit the manuscript.

\section{Acknowledgements}

We are indebted to Dr S Fieni, Prof. D Gramellini and Prof. A BacchiModena from the Department of Obstetrics and Gynaecology of the University of Parma, Italy, for helping to collect the biological material and providing clinical data. Preliminary data of this study were presented as an abstract, selected as top-rated basic abstract, at the 47th Annual Meeting of the European Society for Paediatric Endocrinology (ESPE), Istanbul, dated 20-23 September 2008.

\section{References}

1 Hofman PL, Cutfield WS, Robinson EM, Bergman RN, Menon RK, Sperling MA \& Gluckman PD. Insulin resistance in short children with intrauterine growth retardation. Journal of Clinical Endocrinology and Metabolism 199782 402-406. (doi:10.1210/jc.82.2.402)
2 Geremia C \& Cianfarani S. Insulin sensitivity in children born small for gestational age (SGA). Review of Diabetic Studies $2004 \mathbf{1}$ 58-65. (doi:10.1900/RDS.2004.1.58)

3 Weiss R, Dziura J, Burgert TS, Tamborlane WW, Taksali SE, Yeckel CW, Allen K, Lopees M, Savoye M, Morrison J, Sherwin RS \& Caprio S. Obesity and the metabolic syndrome in children and adolescents. New England Journal of Medicine $2004 \mathbf{3 5 0}$ 2362-2374. (doi:10.1056/NEJMoa031049)

4 Cianfarani S, Martinez C, Maiorana A, Sciré G, Spadoni GL \& Boemi S. Adiponectin levels are reduced in children born small for gestational age and are inversely related to postnatal catch-up growth. Journal of Clinical Endocrinology and Metabolism $2004 \mathbf{8 9}$ 1346-1351. (doi:10.1210/jc.2003-031704)

5 Chen J, Tan B, Karteris E, Zervou S, Digby J, Hillhouse EW, Vatisch M \& Randeva HS. Secretion of adiponectin by human placenta: differential modulation of adiponectin and its receptors and its receptors by cytokines. Diabetologia 200649 1292-1302. (doi:10.1007/s00125-006-0194-7)

6 Alonso A, Del Rey CG, Navarro A, Tolivia J \& Gonzalez CG. Effects of gestational diabetes mellitus on proteins implicated in insulin signalling in human placenta. Gynecological Endocrinology 2006 22 526-535. (doi:10.1080/09513590600921374)

7 Barbour LA, McCurdy CE, Hernandez TL, Kirwan JP, Catalano PM \& Friedman JE. Cellular mechanisms for insulin resistance in normal pregnancy and gestational diabetes. Diabetes Care 200730 S112-S119. (doi:10.2337/dc07-s202)

8 Scioscia M, Gumaa K, Kunjara S, Paine MA, Selvaggi LE, Rodeck $\mathrm{CH} \&$ Rademacher TW. Insulin resistance in human preeclamptic placenta is mediated by serine phosphorylation of insulin receptor substrate-1 and -2. Journal of Clinical Endocrinology and Metabolism 200691 709-717. (doi:10.1210/jc.2005-1965)

9 Hwang JH, Lee MJ, Seok OS, Paek YC, Cho GJ, Seol HJ, Lee JK \& Oh MJ. Cytokine expression in placenta-derived mesenchymal stem cells in patients with pre-eclampsia and normal pregnancies. Cytokine 201049 95-101. (doi:10.1016/j.cyto.2009.08.013)

10 Street ME, Volta C, Ziveri MA, Viani I \& Bernasconi S. Markers of insulin sensitivity in placentas and cord serum of intrauterine growth restricted (IUGR) newborns. Clinical Endocrinology 2009 71 394-399. (doi:10.1111/j.1365-2265.2009.03533.x)

11 Street ME, Seghini P, Fieni S, Ziveri MA, Volta C, Martorana D, Viani I, Gramellini D \& Bernasconi S. Changes in interleukin-6 and IGF system and their relationships in placenta and cord blood in newborns with fetal growth restriction compared with controls. European Journal of Endocrinology 2006155 567-574. (doi:10. 1530/eje.1.02251)

12 Fowden AL \& Forhead AJ. Endocrine regulation of feto-placental growth. Hormone Research 200972 257-265. (doi:10.1159/ 000245927)

13 Senn JJ, Klover PJ, Nowak IA \& Mooney RA. Interleukin-6 induces cellular insulin resistance in hepatocytes. Diabetes 200251 3391-3399. (doi:10.2337/diabetes.51.12.3391)

14 Ozes ON, Akca H, Mayo LD, Gustin JA, Maehama T, Dixon JE \& Donner DB. A phosphatidylinositol 3-kinase/Akt/mTOR pathway mediates and PTEN antagonizes tumor necrosis factor inhibition of insulin signalling through insulin receptor substrate-1. PNAS 200198 4640-4645. (doi:10.1073/pnas.051042298)

15 Klover PJ, Zimmers TA, Koniaris LG \& Mooney RA. Chronic exposure to interleukin- 6 causes hepatic insulin resistance in mice. Diabetes 200352 2784-2789. (doi:10.2337/diabetes.52. $11.2784)$

16 Li Y, Devadoss JS, Sundaraj KP, Lopes-Virella MF \& Huang Y. IL-6 and high glucose synergistically upregulate MMP-1 expression by U937 mononuclear phagocytes via ERK $1 / 2$ and JNK pathways and c-Jun. Journal of Cellular Biochemistry $2010110248-259$. (doi:10.1002/jcb.22532)

17 Aguirre V, Werner ED, Giraud J, Lee YH, Shoelson SE \& White MF. Phosphorylation of Ser307 in insulin receptor substrate-1 blocks interactions with the insulin receptor and inhibits insulin action. Journal of Biological Chemistry 2002277 1531-1537. (doi:10. 1074/jbc.M101521200) 
18 Mooney RA, Senn J, Cameron S, Inamdar N, Boivin LH, Shang Y \& Furlanetto RW. Suppressors of cytokine signalling-1 and -6 associate with and inhibit the insulin receptor. Journal of Biological Chemistry 2001276 25889-25893. (doi:10.1074/ jbc.M010579200)

19 Senn JJ, Klover PJ, Nowak IA, Zimmers TA, Koniaris LG, Furlanetto RW \& Mooney RA. Suppressor of cytokine signaling3 (SOCS-3), a potential mediator of interleukin-6-dependent insulin resistance in hepatocytes. Journal of Biological Chemistry 2003278 13740-13746. (doi:10.1074/jbc.M210689200)

20 LeRoith D \& Nissley P. Knock your SOCS off!. Journal of Clinical Investigation 2005115 233-236. (doi:10.1172/JCI24228)

21 Gagliardi L, Macagno D, Pedrotti D, Coraiola M, Furlan R, Agostinis L \& Milani S. Weight, length, and head circumference at birth of a north-eastern italian population, report of the ad hoc committee of the italian society of neonatology. Italian Journal of Pediatrics 199925 159-169.

22 Zhang J, Merialdi M, Platt LD \& Kramer MS. Defining normal and abnormal fetal growth: promises and challenges. American Journal of Obstetrics and Gynecology 2010202 522-528. (doi:10. 1016/j.ajog.2009.10.889)

23 Gual P, Marchand-Brustel Y \& Tanti JF. Positive and negative regulation of insulin signalling through IRS-1 phosphorylation. Biochimie 200587 99-109. (doi:10.1016/j.biochi.2004.10.019)

24 Boura-Halfon S \& Zick Y. Phosphorylation of IRS proteins, insulin action, and insulin resistance. American Journal of Physiology. Endocrinology and Metabolism 2009296 E581-E591. (doi:10. 1152/ajpendo.90437.2008)

25 Yung HW, Calabrese S, Hynx D, Hemmings BA, Cetin I, CharnokJones DS \& Burton GJ. Evidence of placental translation inhibition and endoplasmic reticulum stress in the etiology of human intrauterine growth restriction. American Journal of Pathology 2008173 451-462. (doi:10.2353/ajpath.2008.071193)

26 Laviola L, Perrini S, Belanti G, Natalicchio A, Montrone C, Leonardini A, Vimercati A, Scioscia M, Selvaggi L, Giorgino R, Greco P \& Giorgino F. Intrauterine growth restriction in humans is associated with abnormalities in placental insulin-like growth factor signaling. Endocrinology 2005146 1498-1505. (doi:10. 1210/en.2004-1332)

$27 \mathrm{Wu}$ TH \& Lin CH. IL-6 mediated alterations on immobile behavior of rats in the forced swim test via ERK1/2 activation in specific brain regions. Behavioural Brain Research 2008193 183-191. (doi:10.1016/j.bbr.2008.05.009)

28 Andreozzi F, Laratta E, Procopio C, Hribal ML, Sciacqua A, Perticone M, Miele C, Perticone F \& Sesti G. Interleukin-6 impairs the insulin signaling pathway, promoting production of nitric oxide in human umbilical vein endothelial cells. Molecular and Cellular Biology 200727 2372-2383. (doi:10.1128/MCB. 01340-06)

29 Emanuelli B, Peraldi P, Filloux C, Ssawka-Verhelle D, Hilton D \& Van Obberghen E. SOCS-3 is an insulin-induced negative regulator of insulin signalling. Journal of Biological Chemistry 2000275 15985-15891. (doi:10.1074/jbc.275.21.15985)

30 Dey BR, Spence SL, Nissley P \& Furlanetto RW. Interaction of human suppressor of cytokine signalling (SOCS)-2 with the insulin-like growth factor-I receptor. Journal of Biological Chemistry 1998273 24095-24101. (doi:10.1074/jbc.273.37.24095)

31 Greenhalgh CJ, Rico-Bautista E, Lorentzon M, Thaus AL, Morgan PO, Willson TA, Zervoudakis P, Metcalf D, Street I, Nicola NA, Nash AD, Fabri LJ, Norstedt G, Ohlsson C, FloresMorales A, Alexander WS \& Hilton DJ. SOCS2 negatively regulates growth hormone action in vitro and in vivo. Journal of Clinical Investigation 2005115 397-406. (doi:10.1172/JCI22710)

32 Ohlsson C, Mohan S, Sjogren K, Tivesten A, Isgaard J, Isaksson O, Jansson J-O \& Svensson J. The role of liver-derived insulin-like growth factor-I. Endocrine Reviews 200930 494-535. (doi:10. 1210/er.2009-0010)

33 Barnes KM \& Miner JL. Role of resistin in insulin sensitivity in rodents and humans. Current Protein \& Peptide Science 200910 96-107. (doi:10.2174/138920309787315239)

34 Hotamisligil GS. The irresistible biology of resistin. Journal of Clinical Investigation 2003111 173-174. (doi:10.1172/JCI17605)

35 Colomiere M, Permezel M, Riley C, Desoye G \& Lappas M. Defective insulin signaling in placenta from pregnancies complicated by gestational diabetes mellitus. European Journal of Endocrinology 2009160 567-578. (doi:10.1530/EJE-09-0031)

36 Ziemke F \& Mantzoros CS. Adiponectin in insulin resistance: lessons from translational research. American Journal of Clinical Nutrition 201091 258S-261S. (doi:10.3945/ajcn.2009.28449C)

37 Kleiblova P, Dostalova I, Bartlova M, Lacinova Z, Ticha I, Krejci V, Springer D, Kleibl Z \& Haluzik M. Expression of adipokines and estrogen receptors in adipose tissue and placenta of patients with gestational diabetes mellitus. Molecular and Cellular Endocrinology 2010314 150-156. (doi:10.1016/j.mce.2009.08.002)

Received 28 September 2010

Accepted 7 October 2010 